\title{
SISTEM PENDUKUNG KEPUTUSAN PEMILIHAN SUPERVISOR PERENCANAAN TERBAIK MENERAPKAN PREFERENCE SELECTION INDEX DI PT. PLN (PERSERO) AREA MEDAN
}

\author{
Nurul Huda, Mesran, Siti Nurhabibah Hutagalung \\ Sekolah Tinggi Manajemen Informatika STMIK Budi Darma, Indonesia \\ Jalan Sisingamangaraja No. 338 Medan, Indonesia
}

\section{PENDAHULUAN}

Setiap perusahaan menjalankan fungsi-fungsi yang terdapat pada manajemen, perusahaan tersebut harus memiliki suatu perencanaan yang terdefinisi dengan baik. Adanya suatu perencanaan dalam suatu perusahaan sangat berpengaruh terhadap proses kinerja dalam jangka waktu ketergantungan untuk memperoleh hasil manajemen yang baik, oleh karena itu manajer di perusahaan tersebut harus mampu menguasai keseluruhan dari fungsi manajemen yang ada. Salah satunya fungsi dari planning (perencanaan) yang di pimpin untuk perkembangan perusahaan itu sendiri dengan tujuan kepemimpianan yang menjadi pedoman awal untuk karyawaan bawahan yang di pimpinnya. Sehingga akan memperoleh hasil kinerja yang maksimal dengan tujuan memperhatikan sumber daya pada setiap perusahaan agar terus bertahan, maju dan berkembang dengan pengawasan langsung dari kinerja seorang pemimpin yang efektif dan efesien.

\subsection{Perumusan Masalah}

Berdasarkan uraian permasalahan pada latar belakang di atas, maka penulis membuat rumusan masalah yang dihadapi sebagai berikut:

1. Bagaimana prosedur dalam pemilihan supervisor perencanaan terbaik di PT. PLN (Persero) Area Medan?

2. Bagaimana menerapkan metode Preference Selection Index (PSI) pada pemilihan supervisor perencanaan terbaik di PT. PLN (Persero) Area Medan?

3. Bagaimana merancang aplikasi pemilihan supervisor perencanaan terbaik di PT. PLN (Persero) Area Medan menggunakan Visual Basic Net 2008?

\subsection{Tujuan Penelitian}

Adapun tujuan dari penelitian ini adalah sebagai berikut:

1. Untuk mengetahui prosedur dalam pemilihan supervisor perencanaan terbaik di PT. PLN (Persero) Area Medan.

2. Menerapkan metode Preference Selection Index (PSI) pada pemilihan supervisor perencanaan terbaik di PT. PLN (Persero) Area Medan.

3. Merancang aplikasi pemilihan supervisor perencanaan terbaik di PT. PLN (Persero) Area Medan menggunakan Visual Basic Net 2008.

\subsection{Manfaat Penelitian}

Manfaat dari penelitian ini yaitu:

1. Membantu manajemen dalam menghasilkan keputusan yang efektif dalam pemilihan supervisor perencanaan terbaik.

2. Sebagai alternatif sistem yang dapat diusulkan kepada pihak manajemen PT. PLN (Persero) Area Medan, khususnya sistem pendukung keputusan pemilihan supervisor perencanaan terbaik.

\section{ANALISA DAN PEMBAHASAN}

Dalam proses pemilihan supervisor perencanaan terbaik ini, calon supervisor harus memenuhi kriteria-kriteria yang sudah ditetapkan oleh manajer Kepala Bagian masing-masing yang ada di perusahaan tersebut. Proses pemilihan yang cukup ketat karena tahapan atau proses yang harus disesuaikan dari setiap kriteria-kriteria berdasarkan alternatif yang ada dan membutuhkan 
waktu yang cukup lama dan tidak maksimal sehingga menghasilkan sebuah keputusan yang kurang akurat.

Sistem yang berjalan saat ini, PT. PLN (Persero) Area Medan mendapatkan hasil yang kurang akurat dalam mengambil keputusan. Dari masalah pengambilan keputusan yang ada, telah dianalisa permasalahannya untuk membuat suatu sistem yang baru yang lebih efektif diharapkan mampu mengatasi permasalahan dalam pengambilan keputusan pemilihan supervisor perencanaan terbaik sesuai dengan kriteria-kriteria yang sudah ditentukan. Sistem pendukung keputusan pemilihan supervisor perencanaan terbaik ini diharapkan dapat membantu PT. PLN (Persero) Area Medan dalam proses pemilihan supervisor perencanaan terbaik.

\subsection{Data Alternatif}

Data sangat penting dalam sistem pendukung keputusan. Berikut adalah data calon supervisor perencanaan terbaik yang ada di PT. PLN (Persero) Area Medan. Berikut daftar calon supervisor yang akan dipilih dan menjadi alternatif untuk dijadikan perhitungan dengan mengambil sampel beberapa karyawan.

\subsection{Menentukan Kriteria Dan Bobot}

Dalam Proses metode PSI memerlukan kriteria-kriteria yang akan dijadikan bahan perhitungan dan pertimbangan. Adapun kriteria-kriteria yang menjadi bahan perhitungan dan pertimbangan.

Tabel 1. Kriteria

\begin{tabular}{|c|c|}
\hline Kriteria & Keterangan \\
\hline C1 & Berwawasan Luas \\
\hline C2 & Nilai Psikotes \\
\hline C3 & Nilai TOEFL \\
\hline C4 & Kedisiplinan \\
\hline C5 & Masa Kerja \\
\hline
\end{tabular}

Metode PSI (Preference Selection Index) merupakan metode untuk memecahkan multikriteria pengambilan keputusan (MCDM). Dalam metode yang diusulkan itu tidak perlu untuk menetapkan kepentingan relatif antara atribut. Bahkan, tidak ada kebutuhan komputasi bobot atribut yang terlibat dalam pengambilan keputusan dalam metode ini. Metode ini berguna bila ada konflik dalam menentukan kepentingan relatif antar atribut. Dalam metode PSI (Preference Selection Index), hasilnya diperoleh dengan perhitungan minimal dan sederhana seperti apa adanya berdasarkan konsep statistik tanpa keharusan bobot atribut.

Langkah-langkah prosedur PSI dapat dinyatakan, sebagai berikut:

1. Tentukan masalahnya, tentukan tujuan dan mengidentifikasi atribut dan alternatif yang terkait masalah pengambilan keputusan.

2. Merumuskan Matriks Keputusan. Langkah ini melibatkan konstruksi matriks berdasarkan semua informasi yang tersedia yang menggambarkan atribut masalah.

3. Normalisasi Matriks Keputusan. Jika atribut adalah tipe menguntungkan, maka nilai yang lebih besar, jika atributnya adalah tipe yang tidak menguntungkan, maka nilai yang lebih kecil.

4. Menghitung nilai mean dari data yang telah dinormalisasikan. Langkah ini, berarti nilai dari data normal dari setiap atribut dihitung.

5. Menghitung nilai variasi preferensi. Pada langkah ini sebuah nilai variasi preferensi antara nilai setiap atribut dihitung.

6. Menentukan penyimpangan dalam nilai preferensi.

7. Tentukan kriteria bobotnya.

8. Menghitung pemilihan preferensi indeks untuk setiap alternatif.

9. Memilih alternatif yang sesuai. Masing-masing alternatif digolongkan menurut descending atau menaik untuk memudahkan manajerial interpretasi hasilnya. 
Tabel 2. Alternatif Untuk Kriteria

\begin{tabular}{|l|c|c|c|c|c|}
\hline \multirow{2}{*}{ Alternatif } & \multicolumn{5}{|c|}{ Kriteria } \\
\cline { 2 - 6 } & $\begin{array}{c}\text { Berwawasan } \\
\text { Luas }\end{array}$ & $\begin{array}{c}\text { Nilai } \\
\text { Psikotes }\end{array}$ & $\begin{array}{c}\text { Nilai } \\
\text { TOEFL }\end{array}$ & Kedisiplinan & $\begin{array}{c}\text { Masa } \\
\text { Kerja }\end{array}$ \\
\hline HASAN RIYADI & Sangat Luas & Baik & Baik & $\begin{array}{c}\text { Sangat } \\
\text { Disiplin }\end{array}$ & 3 Tahun \\
\hline ONI AFRIYANDI & Luas & Baik & Baik & Disiplin & 3 Tahun \\
\hline $\begin{array}{l}\text { RUDY HERMANSYAH } \\
\text { HARAHAP }\end{array}$ & Luas & Baik & Baik & Disiplin & 3 Tahun \\
\hline $\begin{array}{l}\text { DWI YULIANA SRI } \\
\text { SIMANJUNTAK }\end{array}$ & Luas & Sangat Baik & Baik & Disiplin & 4 Tahun \\
\hline PURWITO & Sangat Luas & Baik & $\begin{array}{c}\text { Cukup } \\
\text { Baik }\end{array}$ & Sisiplin & 5 Tahun \\
\hline GORGA SIANTURI & Luas & Baik & $\begin{array}{c}\text { Sangat } \\
\text { Baik }\end{array}$ & $\begin{array}{c}\text { Cukup } \\
\text { Disiplin }\end{array}$ & 5 Tahun \\
\hline KEPLER LUBIS & Sangat Luas & Baik & Baik & Disiplin & 3 Tahun \\
\hline MUHAMMAD NASIR & Luas & Sangat Baik & $\begin{array}{c}\text { Sangat } \\
\text { Baik }\end{array}$ & $\begin{array}{c}\text { Cukup } \\
\text { Disiplin }\end{array}$ & 4 Tahun \\
\hline HISAR SIMBOLON & Luas & Baik & $\begin{array}{c}\text { Sangat } \\
\text { Baik }\end{array}$ & $\begin{array}{c}\text { Cukup } \\
\text { Disiplin }\end{array}$ & 5 Tahun \\
\hline LARY ARITONANG & & & Tahun \\
\hline
\end{tabular}

Berikut tabel rating kecocokan dari setiap alternatif pada kriteria yang sudah ditentukan. Tabel 3. Rating Kecocokan dari setiap alternatif pada setiap kriteria

\begin{tabular}{|c|c|c|c|c|c|}
\hline \multirow{2}{*}{ Alternatif } & \multicolumn{5}{|c|}{ Kriteria } \\
\cline { 2 - 6 } & C1 & C2 & C3 & C4 & C5 \\
\hline A1 & 85 & 75 & 80 & 85 & 60 \\
\hline A2 & 70 & 65 & 80 & 75 & 60 \\
\hline A3 & 70 & 80 & 75 & 75 & 70 \\
\hline A4 & 75 & 85 & 65 & 70 & 85 \\
\hline A5 & 80 & 75 & 60 & 70 & 90 \\
\hline A6 & 85 & 90 & 60 & 85 & 90 \\
\hline A7 & 75 & 70 & 80 & 60 & 85 \\
\hline A8 & 90 & 70 & 70 & 65 & 60 \\
\hline A9 & 85 & 85 & 90 & 60 & 65 \\
\hline A10 & 75 & 70 & 90 & 65 & 85 \\
\hline
\end{tabular}

Matriks keputusan yang dibentuk dari tabel kecocokan adalah sebagai berikut:

$$
X=\left[\begin{array}{lllll}
85 & 75 & 80 & 85 & 60 \\
70 & 65 & 80 & 75 & 60 \\
70 & 80 & 75 & 75 & 70 \\
75 & 85 & 65 & 70 & 85 \\
80 & 75 & 60 & 70 & 90 \\
85 & 90 & 60 & 85 & 90 \\
75 & 70 & 80 & 60 & 85 \\
90 & 70 & 70 & 65 & 60 \\
85 & 85 & 90 & 60 & 65 \\
75 & 70 & 90 & 65 & 85
\end{array}\right]
$$


Untuk menyelesaikan masalah diatas dengan metode PSI akan dilakukan sesuai dengan langkah-langkah yang telah dijelaskan.

1. Tentukan masalahnya.

\begin{tabular}{|c|c|c|c|c|c|}
\hline \multirow{2}{*}{ Alternatif } & \multicolumn{5}{|c|}{ Kriteria } \\
\cline { 2 - 6 } & C1 & C2 & C3 & C4 & C5 \\
\hline A1 & 85 & 75 & 80 & 85 & 60 \\
\hline A2 & 70 & 65 & 80 & 75 & 60 \\
\hline A3 & 70 & 80 & 75 & 75 & 70 \\
\hline A4 & 75 & 85 & 65 & 70 & 85 \\
\hline A5 & 80 & 75 & 60 & 70 & 90 \\
\hline A6 & 85 & 90 & 60 & 85 & 90 \\
\hline A7 & 75 & 70 & 80 & 60 & 85 \\
\hline A8 & 90 & 70 & 70 & 65 & 60 \\
\hline A9 & 85 & 85 & 90 & 60 & 65 \\
\hline A10 & 75 & 70 & 90 & 65 & 85 \\
\hline Max & 90 & 90 & 90 & 85 & 90 \\
\hline Min & 70 & 65 & 60 & 60 & 60 \\
\hline
\end{tabular}

2. Merumuskan Matriks Keputusan (3.1)

$X_{i j}=\left[\begin{array}{lllll}85 & 75 & 80 & 85 & 60 \\ 70 & 65 & 80 & 75 & 60 \\ 70 & 80 & 75 & 75 & 70 \\ 75 & 85 & 65 & 70 & 85 \\ 80 & 75 & 60 & 70 & 90 \\ 85 & 90 & 60 & 85 & 90 \\ 75 & 70 & 80 & 60 & 85 \\ 90 & 70 & 70 & 65 & 60 \\ 85 & 85 & 90 & 60 & 65 \\ 75 & 70 & 90 & 65 & 85\end{array}\right]$

3. Normalisasi Matriks Keputusan, dari perhitungan diperoleh matriks $N_{i j}$

$N_{i j}=\left[\begin{array}{ccccc}0.9444 & 0.8333 & 0.8889 & 0.7059 & 1.0000 \\ 0.7778 & 0.7222 & 0.8889 & 0.8 & 1.0000 \\ 0.7778 & 0.8889 & 0.8333 & 0.8 & 0.8571 \\ 0.8333 & 0.9444 & 0.7222 & 0.8571 & 0.7059 \\ 0.8889 & 0.8333 & 0.6667 & 0.8571 & 0.6667 \\ 0.9444 & 1.0000 & 0.6667 & 0.7059 & 0.6667 \\ 0.8333 & 0.7778 & 0.8889 & 1.0000 & 0.7059 \\ 1.0000 & 0.7778 & 0.7778 & 0.9231 & 1.0000 \\ 0.9444 & 0.9444 & 1.0000 & 1.0000 & 0.9231 \\ 0.8333 & 0.7778 & 1.0000 & 0.9231 & 0.7059\end{array}\right]$

Melakukan penjumlahan matriks $N_{i j}$ dari setiap atribut $\sum_{i=1}^{n} N_{i j}=N_{11}+N_{21}+N_{31}+N_{41}+$

$$
\begin{aligned}
\sum_{i=1}^{n} N_{51}+\cdots+N_{m n} & \\
\sum_{j 1}= & N_{11}+N_{21}+N_{31}+N_{41}+N_{51}+N_{61}+N_{71}+N_{81}+N_{91}+N_{101} \\
= & 0.9444+0.7778+0.7778+0.8333+0.8889+0.9444+0.8333+ \\
& 1.0000+0.9444+0.8333 \\
= & 8.7776 \\
\sum_{i=1}^{n} N_{j 2}= & N_{12}+N_{22}+N_{32}+N_{42}+N_{52}+N_{62}+N_{72}+N_{82}+N_{92}+N_{102}
\end{aligned}
$$




$$
\begin{aligned}
= & 0.8333+0.7222+0.8889+0.9444+0.8333+1.0000+0.7778+ \\
& 0.7778+0.9444+0.7778 \\
= & 8.4999
\end{aligned}
$$

Hasil yang diperoleh dari perhitungan di atas adalah sebagai berikut:

$$
\sum_{i=1}^{n} N_{i j}=\left[\begin{array}{lllll}
8.7776 & 8.4999 & 8.3334 & 8.5722 & 8.2313
\end{array}\right]
$$

4. Menghitung nilai mean dari data yang telah dinormalisasi

Hasil dari perhitungan di atas mendapatkan nilai mean yaitu:

$\mathrm{N}=\left[\begin{array}{lllll}0.8778 & 0.8500 & 0.8333 & 0.8572 & 0.8231\end{array}\right]$

5. Menghitung nilai variasi preferensi.

Hasil perhitungan pangkat pada matriks $\phi_{j}$

$\phi_{\mathrm{j}}=\left[\begin{array}{ccccc}0.0044 & 0.0003 & 0.0040 & 0.0229 & 0.0313 \\ 0.01 & 0.0163 & 0.0040 & 0.0033 & 0.0313 \\ 0.01 & 0.0015 & 0 & 0.0033 & 0.0012 \\ 0.0020 & 0.0089 & 0.0123 & 0 & 0.0137 \\ 0.0001 & 0.0003 & 0.0278 & 0 & 0.0245 \\ 0.0044 & 0.0225 & 0.0278 & 0.0229 & 0.0245 \\ 0.0020 & 0.0052 & 0.0040 & 0.0204 & 0.0137 \\ 0.0149 & 0.0052 & 0.0031 & 0.0043 & 0.0313 \\ 0.0044 & 0.0089 & 0.0278 & 0.0204 & 0.01 \\ 0.0020 & 0.0052 & 0.0278 & 0.0043 & 0.0137\end{array}\right]$

Kemudian menjumlahkan hasil nilai pangkat pada matriks $\phi_{j}$

Hasil matriks $\phi_{j}$

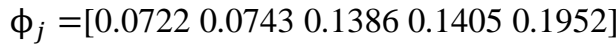

Hasil perhitungan nilai preferensi menghasilkan matriks $\Omega_{j}$

$\Omega_{j}=\left[\begin{array}{lllll}0.9278 & 0.9257 & 0.8614 & 0.8595 & 0.8048\end{array}\right]$

Menghitung total nilai keseluruhan pada matriks $\Omega_{j}$

$\sum \Omega_{j}=0.9278+0.9257+0.8614+0.8595+0.8048=4.3792$

6. Tentukan kriteria bobotnya (3.7)

$$
\begin{aligned}
& \omega_{j}=\frac{0.9278}{4.3792}=0.2119 \\
& \omega_{j}=\frac{0.9257}{4.3792}=0.2114 \\
& \omega_{j}=\frac{0.8614}{4.3792}=0.1967 \\
& \omega_{j}=\frac{0.8595}{4.3792}=0.1963 \\
& \omega_{j}=\frac{0.8048}{4.3792}=0.1838
\end{aligned}
$$

Hasil perhitungan nilai keseluruhan kriteria bobotnya $\omega_{j}$

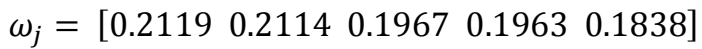

7. Hitung PSI (3.8)

Hasil perhitungan perkalian pada matriks $\theta_{i}$ 


$\theta_{i}=\left[\begin{array}{lllll}0.2001 & 0.1762 & 0.1748 & 0.1386 & 0.1838 \\ 0.1648 & 0.1527 & 0.1748 & 0.1570 & 0.1838 \\ 0.1648 & 0.1880 & 0.1640 & 0.1570 & 0.1575 \\ 0.1766 & 0.1996 & 0.1420 & 0.1682 & 0.1297 \\ 0.1884 & 0.1762 & 0.1311 & 0.1682 & 0.1225 \\ 0.2001 & 0.2114 & 0.1311 & 0.1386 & 0.1225 \\ 0.1766 & 0.1644 & 0.1748 & 0.1963 & 0.1297 \\ 0.2119 & 0.1644 & 0.1530 & 0.1812 & 0.1838 \\ 0.2001 & 0.1996 & 0.1967 & 0.1963 & 0.1697 \\ 0.1766 & 0.1644 & 0.1967 & 0.1812 & 0.1297\end{array}\right]$

Hasil akhir pada matriks $\theta_{i}$

$$
\theta_{i}=\left[\begin{array}{l}
0.8735 \\
0.8331 \\
0.8313 \\
0.8161 \\
0.7864 \\
0.8037 \\
0.8418 \\
0.8943 \\
0.9624 \\
0.8486
\end{array}\right]
$$

8. Hasil akhir masing-masing alternatif digolongkan menurut descending atau menaik untuk memudahkan manajerial interpretasi hasilnya.

Tabel 4. Nilai Untuk Masing-masing Alternatif

\begin{tabular}{|c|c|c|}
\hline Alternatif & Keterangan & Nilai \\
\hline A1 & Hasan Riyadi & 0.8735 \\
\hline A2 & Oni Afriyandi & 0.8331 \\
\hline A3 & Rudy Hermansyah Harahap & 0.8313 \\
\hline A4 & Dwi Yuliana Sri Simanjuntak & 0.8161 \\
\hline A5 & Purwito & 0.7864 \\
\hline A6 & Gorga Sianturi & 0.8037 \\
\hline A7 & Kepler Lubis & 0.8418 \\
\hline A8 & Muhammad Nasir & 0.8943 \\
\hline A9 & Hisar Simbolon & 0.9624 \\
\hline A10 & Lary Aritonang & 0.8486 \\
\hline
\end{tabular}

Tabel 5. Alternatif Digolongkan dari Nilai Tertinggi

\begin{tabular}{|c|c|c|c|}
\hline Alternatif & Keterangan & Nilai & Ranking \\
\hline A9 & Hisar Simbolon & 0.9624 & 1 \\
\hline A8 & Muhammad Nasir & 0.8943 & 2 \\
\hline A1 & Hasan Riyadi & 0.8735 & 3 \\
\hline A10 & Lary Aritonang & 0.8486 & 4 \\
\hline A7 & Kepler Lubis & 0.8418 & 5 \\
\hline A2 & Oni Afriyandi & 0.8331 & 6 \\
\hline A3 & Rudy Hermansyah Harahap & 0.8313 & 7 \\
\hline A4 & Dwi Yuliana Sri Simanjuntak & 0.8161 & 8 \\
\hline A6 & Gorga Sianturi & 0.8037 & 9 \\
\hline A5 & Purwito & 0.7864 & 10 \\
\hline
\end{tabular}


Flowchart adalah penggambaran secara grafik dari langkah-langkah dan urut-urutan prosedur dari suatu program. Flowchart menolong analis dan programmer untuk memecahkan masalah kedalam segmen-segmen yang lebih kecil dan menolong dalam menganalisis alternatifalternatif lain dalam pengoperasian.

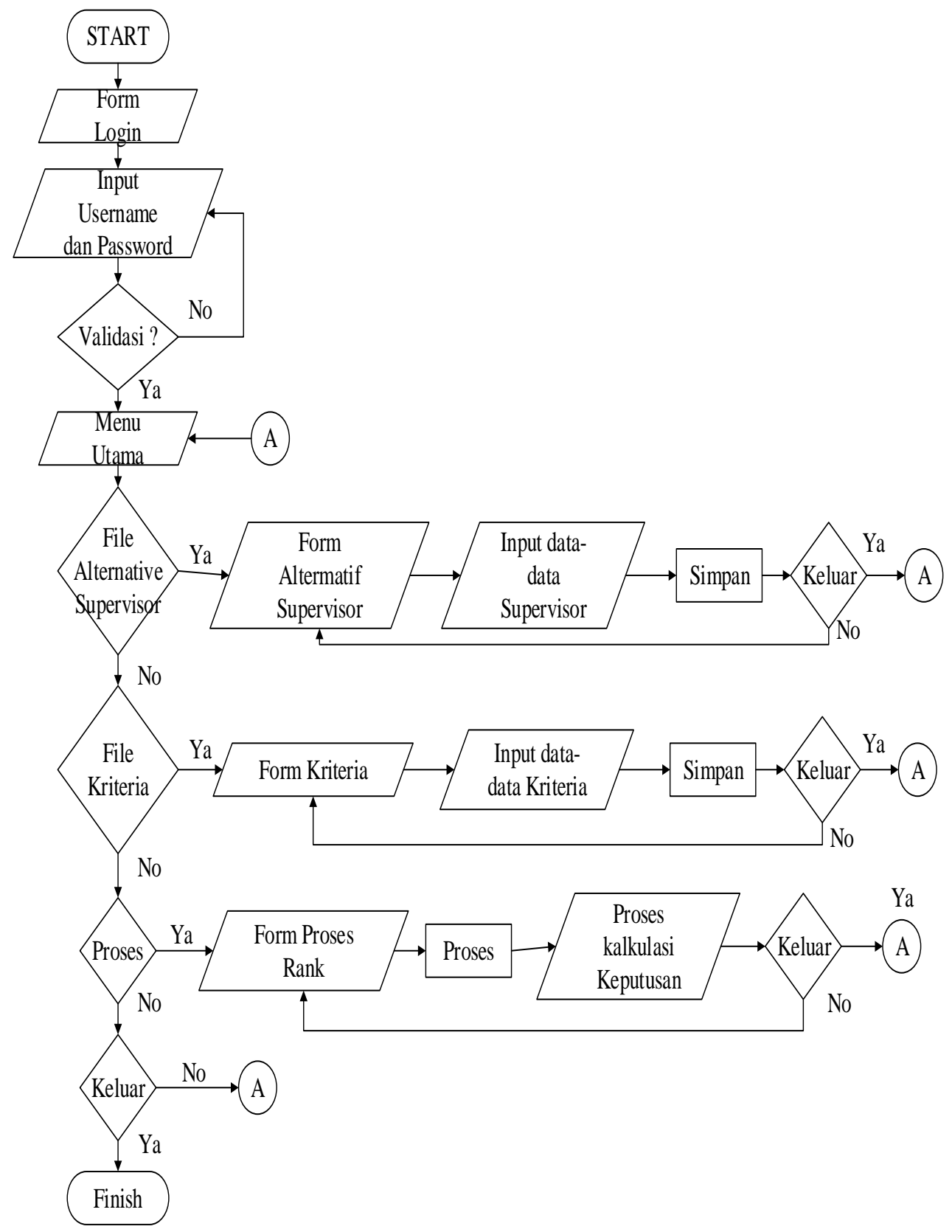

Gambar 2. Flowchart

\section{KESIMPULAN}

Dari penelitian di atas dapat diambil beberapa kesimpulan:

1. Metode PSI mampu menghasilkan bobot dalam perhitungan, untuk mencari alternatif yang terbaik. 
2. Metode Preference Selection Index memberikan keputusan yang lebih efektif di bending metode SAW, WP ataupun MOORA.

\section{REFERENSI}

[1] S. W. Pasaribu, E. Rajagukguk, M. Sitanggang, R. Rahim, and L. A. Abdillah, "Implementasi Multi-Objective Optimization On The Basis Of Ratio Analysis ( MOORA ) Untuk Menentukan Kualitas Buah Mangga Terbaik," J. Ris. Komput., vol. 5, no. 1, pp. 50-55, 2018.

[2] N. Sutrikanti, H. Situmorang, Fachrurrazi, H. Nurdiyanto, and M. Mesran, "Implementasi Pendukung Keputusan Dalam Pemilihan Calon Peserta Cerdas Cermat Tingkat SMA Menerapkan Metode VIKOR,” J. Ris. Komput. (JURIKOM, vol. 5, no. 2407-389X, pp. 109-113, 2018.

[3] Mesran, R. K. Hondro, M. Syahrizal, A. P. U. Siahaan, R. Rahim, and Suginam, "Student Admission Assessment using Multi-Objective Optimization on the Basis of Ratio Analysis (MOORA)," J. Online Jar. COT POLIPT, vol. 10, no. 7, pp. 1-6, 2017.

[4] N. W. Al-Hafiz, Mesran, and Suginam, "Sistem Pendukung Keputusan Penentukan Kredit Pemilikan Rumah Menerapkan Multi-Objective Optimization on the Basis of Ratio Analysis ( Moora )," KOMIK (Konferensi Nas. Teknol. Inf. dan Komputer), vol. I, no. 1, pp. 306-309, 2017.

[5] I. Saputra, S. I. Sari, and Mesran, "PENERAPAN ELIMINATION AND CHOICE TRANSLATION REALITY ( ELECTRE ) DALAM PENENTUAN KULKAS TERBAIK,” KOMIK (Konferensi Nas. Teknol. Inf. dan Komputer), vol. I, pp. 295-305, 2017.

[6] Mesran, G. Ginting, Suginam, and R. Rahim, "Implementation of Elimination and Choice Expressing Reality ( ELECTRE ) Method in Selecting the Best Lecturer ( Case Study STMIK BUDI DARMA )," Int. J. Eng. Res. Technol. (IJERT, vol. 6, no. 2, pp. 141-144, 2017.

[7] H. Nurdiyanto and Heryanita Meilia, "SISTEM PENDUKUNG KEPUTUSAN PENENTUAN PRIORITAS PENGEMBANGAN INDUSTRI KECIL DAN MENENGAH DI LAMPUNG TENGAH MENGGUNAKAN ANALITICAL HIERARCHY PROCESS (AHP)," in Seminar Nasional Teknologi Informasi dan Multimedia 2016, 2016, no. February, pp. 1-7.

[8] P. Umami, L. A. Abdillah, and I. Z. Yadi, "Sistem pendukung keputusan pemberian beasiswa bidik misi," in Konferensi Nasional Sistem Informasi (KNSI2014), 2014.

[9] A. J. Putra, L. A. Abdillah, and H. Yudiastuti, "Penentuan sekolah dasar negeri terbaik kota Palembang dengan metode weighted sum model (WSM) dan weighted product model (WPM) menggunakan visual basic.net 2015," Sentikom, no. September, pp. 1-6, 2016.

[10] Yuhandri, "PENERAPAN DECISSION SUPPORT SYSTEM (DSS) DALAM PEMILIHAN JUDUL PKL DAN SKRIPSI STUDI KASUS UNIVERSITAS PUTRA INDONESIA YPTK PADANG," Maj. Ilm. UPI-YPTK, vol. 1, no. $1,2012$.

[11] H. Nurdiyanto and E. Vem, "PERFORMANCE EVALUATION DECISION SUPPORT SYSTEM USING THE LECTURER ANALITYCAL HIERARCHY PROCESS (CASE STUDY: STMIK DHARMA WACANA METRO),” J. Teknol. Inf. Magister, vol. 1, no. 1, pp. 1-16, Feb. 2016.

[12] A. S. R. A. Binjori, H. R. B. Hutapea, M. Syahrizal, and N. Kurniasih, "Sistem Pendukung Keputusan Penentuan Handphone Bekas Terbaik Menggunakan Metode Multi-Objective Optimization on The Basis of Ratio Analysis ( MOORA )," J. Ris. Komput., vol. 5, no. 1, pp. 61-65, 2018.

[13] K. Umam, V. E. Sulastri, T. Andiri, D. U. Sutiksno, and Mesran, "Perancangan Sistem Pendukung Keputusan Penentuan Prioritas Produk Unggulan Daerah Menggunakan Metode VIKOR,” J. Ris. Komput., vol. Vol 5, no. 1, pp. 43-49, 2018.

[14] J. Simarmata, Pengenalan Teknologi Komputer dan Informasi. Yogyakarta: Andi, 2006.

[15] J. Simarmata, Rekayasan Perangkat Lunak. Bandung: Andi Offset, 2015.

[16] S. Barus, V. M. Sitorus, D. Napitupulu, M. Mesran, and S. Supiyandi, "Sistem Pendukung Keputusan Pengangkatan Guru Tetap Menerapkan Metode Weight Aggregated Sum Product Assesment ( WASPAS )," MEDIA Inform. BUDIDARMA, vol. 2, no. 2, pp. 10-15, 2018.

[17] D. U. Sutiksno, S. Saptenno, M. Tangnga, and A. Shiratina, "Building The Tourist Trust Based on Integrated Marketing Communication and Tourist Experience," in The Global Advanced Research Conference on Management and Business Studies (GARCOMBS), 2015.

[18] S. Kusumadewi, S. Hartati, A. Harjoko, and R. Wardoyo, Fuzzy Multi-Attribute Decision Making (Fuzzy MADM). Yogyakarta: Graha Ilmu, 2006.

[19] Kusrini, Konsep dan Aplikasi Sistem Pendukung Keputusan. Yogyakarta: Andi, 2007.

[20] D. Assrani, N. Huda, R. Sidabutar, I. Saputra, and O. K. Sulaiman, "Penentuan Penerima Bantuan Siswa Miskin Menerapkan Metode Multi Objective Optimization on The Basis of Ratio Analysis (MOORA)," Penentuan Penerima Bantu. Siswa Miskin Menerapkan Metod. Multi Object. Optim. Basis Ratio Anal., vol. 5, no. 2407-389X (Media Cetak), pp. 1-5, 2018. 